\title{
Considerations for managing chronic obstructive pulmonary disease in the elderly
}

This article was published in the following Dove Press journal:

Clinical Interventions in Aging

12 December 2013

Number of times this article has been viewed

\section{George E Taffet' \\ James F Donohue ${ }^{2}$ \\ Pablo R Altman ${ }^{3}$}

'Geriatrics Section, Geriatrics and Cardiovascular Sciences, Baylor College of Medicine, The Methodist Hospital, Houston, TX, 'Pulmonary

Diseases and Critical Care Medicine, University of North Carolina, Chapel Hill, NC, ${ }^{3}$ Medical Affairs, Mylan Specialty L.P., Basking Ridge, NJ, USA

\begin{abstract}
Chronic obstructive pulmonary disease (COPD) is common in older people, with an estimated prevalence of $10 \%$ in the US population aged $\geq 75$ years. Inhaled medications are the cornerstone of treatment for COPD and are typically administered by one of three types of devices, ie, pressurized metered dose inhalers, dry powder inhalers, and nebulizers. However, age-related pulmonary changes may negatively influence the delivery of inhaled medications to the small airways. In addition, physical and cognitive impairment, which are common in elderly patients with COPD, pose special challenges to the use of handheld inhalers in the elderly. Health care providers must take time to train patients to use handheld inhalers and must also check that patients are using them correctly on a regular basis. Nebulizers should be considered for patients unable to use handheld inhalers properly. What follows is a review of issues associated with COPD and its treatment in the elderly patient.
\end{abstract}

Keywords: chronic obstructive pulmonary disease, inhaler, device, cognition, disability, comorbidities, maintenance therapy

\section{Introduction}

Over $10 \%$ of the US population aged $\geq 75$ years report having chronic obstructive pulmonary disease (COPD) (Figure 1), ${ }^{1,2}$ and the primary treatment is inhaled medications administered with handheld devices or nebulizers. ${ }^{3}$ The physical and cognitive changes that are common in the elderly, particularly those aged $\geq 75$ years, may interfere with the proper administration of inhaled therapies, resulting in insufficient dosing, jeopardizing health outcomes, reducing quality of life, and adding to the economic burden of COPD. ${ }^{4}$ This review examines the special challenges of inhaled therapy for COPD in older adults and emphasizes the need for personalized selection of treatment for each patient.

\section{Age-related changes in the respiratory system}

Age-related physiologic changes contribute to impaired pulmonary function and to the increased prevalence of COPD with age. In general, these changes include a progressive reduction in compliance of the chest wall, reduction in strength of the respiratory muscles, and anatomical changes to the lung parenchyma and peripheral airways. ${ }^{5,6}$ Changes in thorax shape due to osteoporosis and kyphosis may induce inefficiencies in chest wall mechanics. ${ }^{5,6}$ The functional consequences of these changes are decreased peak inspiratory and expiratory airflows, vital capacity, and efficiency of gas exchange. Hankinson et al studied the spirometry results of 4,634 lifetime nonsmoking US adults without a diagnosis or symptoms
Correspondence: George E Taffet Geriatrics and Cardiovascular Sciences, Baylor College of Medicine, Head of the Division of Geriatrics, The Methodist Hospital, Mail Stop BCM230, Houston, TX 77030, USA

$\mathrm{Tel}+\mathrm{I} 7137985804$

Fax +I 7137986688

Email gtaffet@bcm.edu 


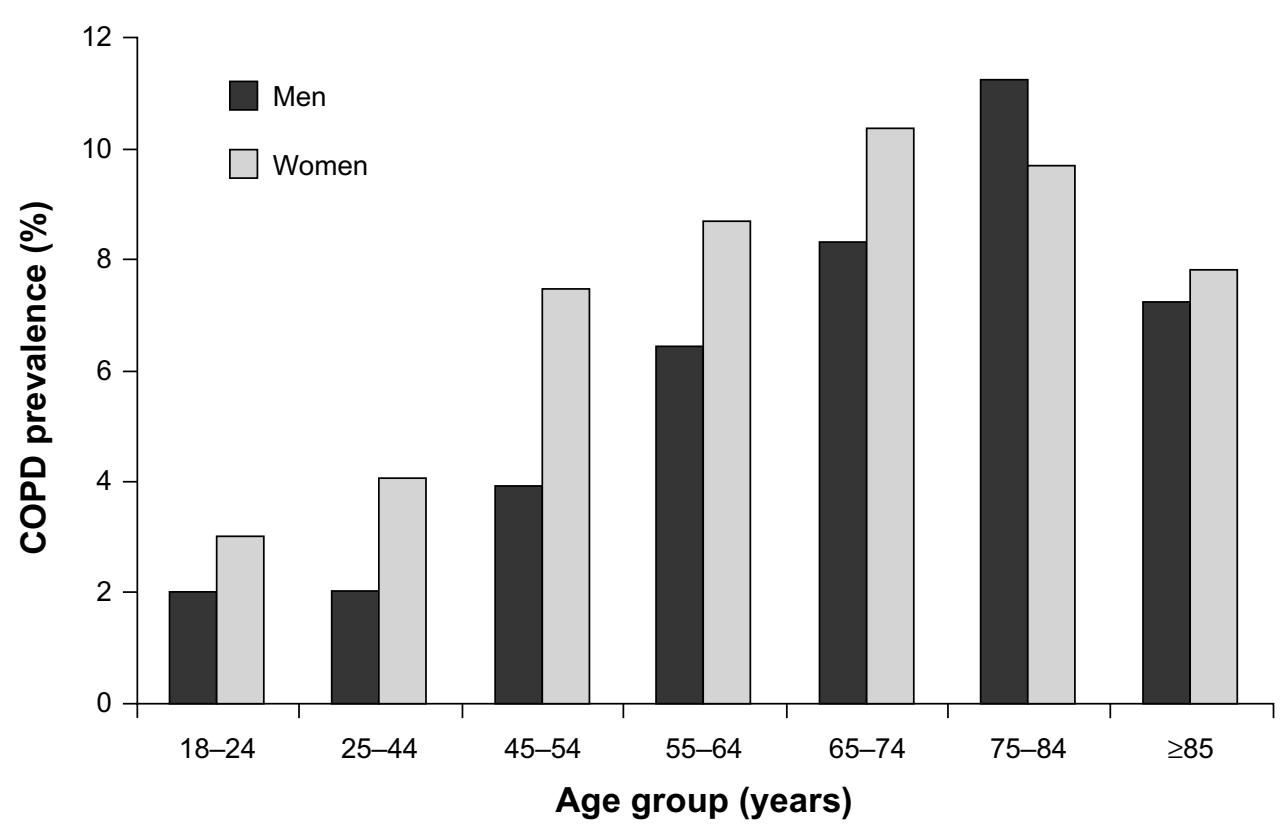

Figure I Prevalence of COPD among adults in the US by age group and gender from 2007 to $2009 .{ }^{1,2}$ Abbreviation: COPD, chronic obstructive pulmonary disease.

of chronic pulmonary disease and found that both men and women demonstrated a reduction of forced expiratory volume in one second $\left(\mathrm{FEV}_{1}\right)$ of about $200-300 \mathrm{~mL}$ every decade between the ages of 20 and 70 years. ${ }^{7}$ Based on their regression model of the observations in this crosssectional study, at age 70 years, $\mathrm{FEV}_{1}$ would be expected to decrease by about $30 \%$ and forced vital capacity (FVC) would be expected to decline by about $20 \%$ compared with values at age 20 years. Importantly, at age 70 years, the expected $\mathrm{FEV}_{1} / \mathrm{FVC}$ ratio would be about $74 \%$, a value approaching the $70 \%$ criterion used for diagnosing significant obstruction. ${ }^{3}$ Additionally, the area for gas exchange declines linearly from the third decade of life and is decreased by one third by about age 85 years. ${ }^{5}$ Loss of elastin leads to increases in residual volume and significant increases in dead space. ${ }^{5}$ All of these changes contribute to an increased likelihood of COPD in the elderly, and critical to geriatric considerations, these age-related changes may be less amenable to treatment.

\section{Diagnosis of COPD in the elderly}

Any elderly patient who smokes or has a history of smoking and demonstrates respiratory symptoms like chronic cough, shortness of breath, or physical activity limitations may have COPD. Spirometry testing is indicated to confirm the diagnosis of COPD and to determine the severity of the disease so that appropriate therapy can be initiated. Although most older people can perform spirometry adequately, ${ }^{8}$ some patients may be unable to perform this test (eg, patients with cognitive impairment, with limitations to vigorous respiratory efforts, sedation). Allen and Baxter ${ }^{9}$ evaluated four tests of cognition for their ability to predict inability to perform spirometry in a group of 113 subjects aged $\geq 70$ (range 74-97) years. Only five of $57(9 \%)$ subjects with a Mini-Mental State Examination score below the threshold for borderline cognitive impairment (Mini-Mental State Examination score $<24^{10}$ ) were able to perform an adequate spirometry test. This observation suggests that, in the large majority of patients with dementia, the diagnosis of COPD will need to be made by clinical means.

In the subset of older patients who are able to perform spirometry, a post-bronchodilator $\mathrm{FEV}_{1} / \mathrm{FVC}$ ratio $<0.70$ is considered diagnostic of COPD. ${ }^{3}$ Table 1 presents the Global Initiative for Chronic Obstructive Lung Disease (GOLD) classification of severity of COPD based on spirometry results. ${ }^{3}$ This classification or risk assessment based on history of COPD exacerbations combined with an assessment of symptoms using the Modified British Medical Research Council Dyspnea Scale or the COPD Assessment Test can be used to assess future risk and guide therapeutic decisions (Table 2). ${ }^{3}$ In patients who are unable to perform spirometry, a smoking history of $>55$ pack-years, wheezing upon auscultation, and (if available) patient self-reported wheezing can be considered evidence 
Table I Classification of severity of airflow limitation in COPD based on post-bronchodilator spirometry

\begin{tabular}{ll}
\hline GOLD category & FEV $_{\mathbf{I}}$ \\
\hline In patients with FEV IFVC $<\mathbf{0 . 7 0}$ & \\
I. Mild & $\mathrm{FEV}_{1} \geq 80 \%$ predicted \\
2. Moderate & $50 \% \leq \mathrm{FEV}_{1}<80 \%$ predicted \\
3. Severe & $30 \% \leq \mathrm{FEV}_{1}<50 \%$ predicted \\
4. Very severe & $\mathrm{FEV}_{1}<30 \%$ predicted \\
\hline
\end{tabular}

Note: Reproduced with permission from the Global Initiative for Chronic Obstructive Lung Disease (GOLD). ${ }^{3}$

Abbreviations: COPD, chronic obstructive pulmonary disease; FEV, forced expiratory volume in one second; FVC, forced vital capacity.

of the presence of airflow obstruction. ${ }^{11}$ In our experience, the group of patients who are unable to perform spirometry require the greatest attention by the geriatrician in individualizing their treatment.

\section{Treatment of COPD in elderly patients}

The primary goals of treatment in older persons with COPD are maximizing their pulmonary function and preventing exacerbations. To address these goals, inhaled medications are the primary pharmacologic agents employed, including

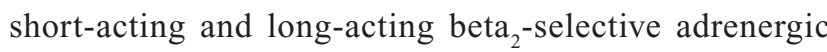
agonists, short-acting and long-acting cholinergic antagonists, and corticosteroids (Table 2). 3,12 These agents are typically administered by one of three types of devices, ie, pressurized metered dose inhalers (MDIs), dry powder inhalers (DPIs), or nebulizers. The age-associated pulmonary changes discussed above, especially those affecting inspiratory capacity, may negatively influence the pulmonary delivery of inhaled medications. Handheld inhalers (ie, pressurized MDIs and DPIs), in particular, pose special challenges in elderly patients. Physical and cognitive impairment, especially common in nursing home patients, may reduce the effectiveness of treatment with these devices. ${ }^{13}$

\section{COPD treatment goals are largely unmet in nursing home patients}

Recent evidence suggests that the goals of reducing symptoms and risks and allowing for an optimal quality of life are largely unmet in elderly patients in nursing homes. A retrospective analysis of 27,106 nursing home residents with COPD (58\% female and $65 \%$ aged $\geq 75$ years) by Zarowitz and O'Shea ${ }^{14}$ showed that $83 \%$ received at least one medication to treat COPD. Forty-nine percent of residents were treated with a nebulized form of short-acting beta-agonists, and 23\% were treated with a nebulized form of a short-acting anticholinergic medication. The use of handheld inhaler devices was less common (15\% for short-acting beta-agonists and $2 \%$ for short-acting anticholinergics). About $42 \%$ of this nursing home population had moderate or severe cognitive impairment based on the Minimum Data Set Cognitive Performance Scale. The preference for nebulized medications suggests that the health care providers recognized these residents often lacked the physical skills or cognitive abilities to correctly use handheld inhaler devices. However, 33\% of residents demonstrated shortness of breath, and 22\% experienced at least two exacerbations during the one-year observation period, suggesting that there was room for improvement in the COPD treatment this group received.

Patients with COPD are often treated with complicated regimens, ${ }^{15}$ and poor eyesight or hearing loss may make it more difficult to adhere to treatment. For example, in a study of factors associated with poor medication adherence in patients with COPD ( $n=276$, average age 71 years), older patients reported that being confused about their medications

Table 2 Initial pharmacologic management of COPD

\begin{tabular}{|c|c|c|c|c|c|c|}
\hline \multirow{2}{*}{$\begin{array}{l}\text { Patient } \\
\text { category }\end{array}$} & \multirow[t]{2}{*}{ Characteristics } & \multicolumn{2}{|c|}{ Risk assessment } & \multicolumn{2}{|c|}{ Symptoms } & \multirow{2}{*}{$\begin{array}{l}\text { Inhaled pharmacologic } \\
\text { management of COPD }\end{array}$} \\
\hline & & $\begin{array}{l}\text { Spirometric } \\
\text { classification }\end{array}$ & $\begin{array}{l}\text { Exacerbations } \\
\text { per year }\end{array}$ & $\begin{array}{l}\text { mMRC } \\
\text { score }\end{array}$ & $\begin{array}{l}\text { CAT } \\
\text { score }\end{array}$ & \\
\hline A & $\begin{array}{l}\text { Low risk } \\
\text { Fewer symptoms }\end{array}$ & GOLD I-2 & $\leq 1$ & $0-1$ & $<10$ & $\begin{array}{l}\text { Short-acting anticholinergic as needed or } \\
\text { Short-acting beta }{ }_{2} \text { agonist as needed }\end{array}$ \\
\hline B & $\begin{array}{l}\text { Low risk } \\
\text { More symptoms }\end{array}$ & GOLD I-2 & $\leq 1$ & $\geq 2$ & $\geq 10$ & $\begin{array}{l}\text { Long-acting anticholinergic or long-acting } \\
\text { beta }_{2} \text { agonist }\end{array}$ \\
\hline C & $\begin{array}{l}\text { High risk } \\
\text { Fewer symptoms }\end{array}$ & GOLD 3-4 & $\geq 2$ & $0-1$ & $<10$ & $\begin{array}{l}\text { Corticosteroid combined with long-acting } \\
\text { anticholinergic or long-acting beta }{ }_{2} \text { agonist }\end{array}$ \\
\hline$D$ & $\begin{array}{l}\text { High risk } \\
\text { More symptoms }\end{array}$ & GOLD 3-4 & $\geq 2$ & $\geq 2$ & $\geq 10$ & $\begin{array}{l}\text { Corticosteroid combined with long-acting } \\
\text { anticholinergic or long-acting beta } \text { agonist }^{-}\end{array}$ \\
\hline
\end{tabular}

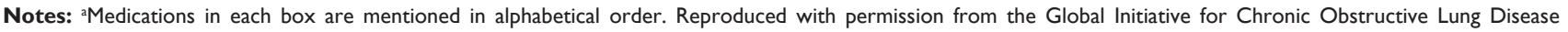
(GOLD). ${ }^{3}$

Abbreviations: CAT, COPD Assessment Test; COPD, chronic obstructive pulmonary disease; mMRC score, modified Medical Research Council score. 
or varying the regimen based on how they felt was highly correlated with poor medication adherence. ${ }^{16}$ Anxiety and depression, common comorbidities in nursing home patients with $\mathrm{COPD},{ }^{17}$ can also be a major deterrent to therapeutic compliance. ${ }^{18,19}$

\section{Inhaled therapy for COPD poses special challenges in elderly adults}

Physical and cognitive changes contribute to the difficulties some elderly patients have with handheld inhalers. ${ }^{13}$ An early study of cognitively impaired patients who were instructed on inhaler use showed that one day after training, 50\% of patients with borderline cognitive impairment could not operate an MDI correctly and $100 \%$ of patients with mild dementia could not operate an MDI correctly. ${ }^{20}$

Worsening hypoxia or hypercapnia from COPD or from a COPD exacerbation can also negatively impact cognitive function, especially in patients who already demonstrate mild cognitive dysfunction. ${ }^{21}$ The hypoxia and hypercapnia seem to impact executive function more than orientation or memory. ${ }^{22}$ Therefore, cognitive assessments and inhaler use assessments made at the time of discharge after a hospitalization for a COPD exacerbation, when pulmonary and associated cognitive functions are likely to be optimal, may provide false reassurance that the patient will have sufficient cognitive ability to properly manage their COPD. When the elderly person with COPD needs to make decisions on increasing medications or calling for advice, their decisionmaking capacity may be less than at baseline.

Loss of physical strength may contribute to difficulty in actuating a pressurized MDI. Gray et al studied a group of 72 subjects (aged 50-87 years) and found that decreased hand strength (measured with a dynamometer) was an independent predictor for incorrect use of a pressurized MDI. ${ }^{23}$ Importantly, they concluded that sufficient hand strength beyond the minimum required to actuate the inhaler was necessary for correct use. The presence of arthritis or joint pain may also contribute to an inability to correctly use a handheld inhaler. Neuromuscular conditions like Parkinson's disease or complications after stroke may also interfere with use of handheld inhalers. ${ }^{13}$

Additional factors that contribute to the difficulties faced by elderly patients with COPD include their comorbidities and the complexity of the accompanying medication regimens. ${ }^{17} \mathrm{~A}$ recent study of 1,003 patients with COPD found that the median number of comorbidities was nine and that the severity of dyspnea increased with the increasing number of comorbid conditions. ${ }^{24}$ Optimal management of the older COPD patient must consider all of their medical issues.

\section{Inhaled therapy devices}

Multiple inhaled medications for COPD are available and are delivered by different devices. The most used devices are MDIs, DPIs, and nebulizers. All have limitations, particularly in elderly adults; error rates increase with age and the severity of airflow obstruction. ${ }^{25-27}$ Within the framework of the challenges that elderly patients with COPD face, as discussed in the preceding paragraphs, the advantages and limitations of these devices for this specific population warrant careful clinical consideration when planning optimal COPD management. ${ }^{28}$

\section{Pressurized MDIs}

The pressurized MDI is a pressurized aerosol canister that contains medication either in solution or suspension in a liquefied gas propellant, usually hydrofluoroalkane. ${ }^{29}$ The primary advantages of this device are that it is compact and portable, offers consistent dosing and rapid delivery, can be used independently and inconspicuously, and sometimes includes a dose counter. On the other hand, the pressurized MDI has been called the most complex dosage form in medicine. ${ }^{29}$

Difficulties using pressurized MDIs are widely documented. A meta-analysis of 24 studies of pressurized MDI use found that $77 \%$ of patients made at least one error during its use. ${ }^{12}$ Inadequate hand-breath coordination, poor fine motor control, and hand or finger muscle weakness from comorbidity, such as arthritis, stroke, or neuromuscular disease, all interfere with proper use. In one study of errors associated with pressurized MDIs, the proper use rate decreased with increasing age, with only $14 \%$ of patients aged $\geq 75$ years using their pressurized MDI correctly (Figure 2). ${ }^{26}$ Todd et al studied a group of 30 independently living, cognitively normal volunteers aged 73-90 years and found that 29 of $30(97 \%)$ were able to learn to use a pressurized MDI correctly, but when retested 24 hours later, the rate of correct use dropped to $36 \% .{ }^{30}$ It is important to note that subjects with upper limb weakness were excluded from this study. Breath-actuated MDIs may mitigate problems with digital manipulation but require sufficient inspiratory flow (usually at least $30 \mathrm{~L} / \mathrm{sec}$ ) to trigger the device. ${ }^{31}$ Different inhaler devices require different techniques, so instruction for use by providers may not be correct. Spacers are used to minimize problems of poor inhalation associated with pressurized MDIs, but they present problems of their own. The walls of the spacers retain some of the drug, making it 


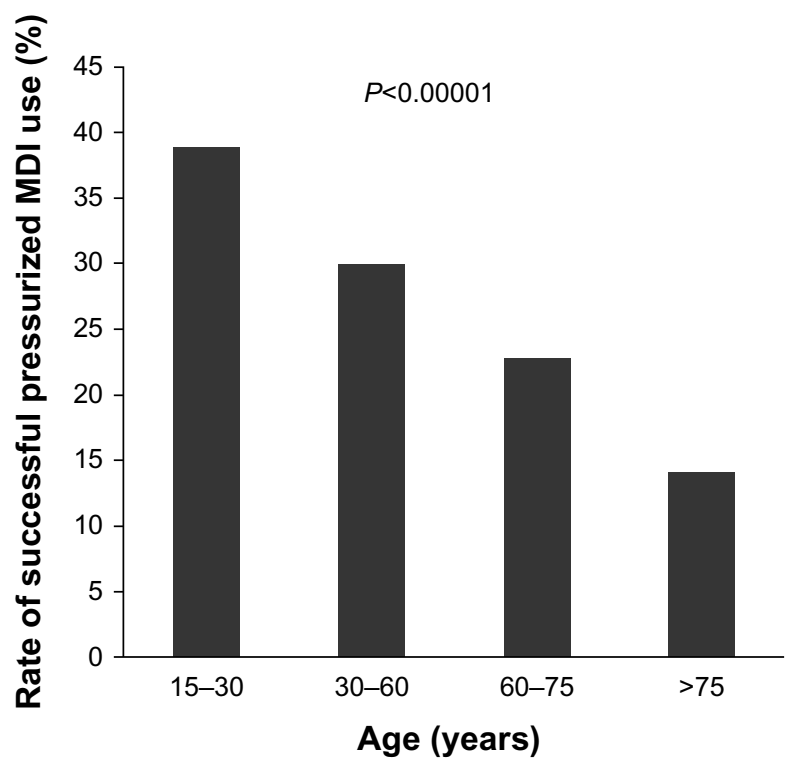

Figure 2 Decrease in frequency of successful use of pressurized MDI with patient age based on data reported by Giraud and Roche. ${ }^{26}$ Results are based on physicians' observations of 3955 patients with asthma who were currently being treated with an inhaled corticosteroid for at least 3 months and an on-demand short-acting betaagonist, both delivered by pressurized MDI. P-value for between-group comparison was calculated by Pearson's Chi-squared test.

Abbreviation: MDI, metered dose inhaler.

impossible to know how much is actually delivered into the airways. Many patients find spacers technically challenging and may prefer not to use them. ${ }^{13}$ The time clinicians spend teaching and assessing how patients use these devices is time well spent. A scheme for assessment of correct pressurized MDI use has been described. ${ }^{32}$

\section{Dry powder inhalers}

The DPI is a breath-actuated device for inhaling medication formulated as a dry powder. Advantages of DPIs are that they do not require coordination of inhalation with activation and do not require hand strength. Therefore, they are easier to use than MDIs. Although DPIs are small and portable with rapid delivery, their use is nonetheless complex. The DPI must be loaded before each inhalation, usually with a capsule containing powder. However, opening the blister packs that contain the medication capsules is one of the most difficult aspects of DPI use for elderly patients. ${ }^{33}$ Once the capsule is loaded, DPIs typically require eight steps for appropriate utilization, ${ }^{34}$ four of which are commonly associated with errors (failure to exhale before actuation, ${ }^{34}$ failure to do a deep and rapid inhalation, ${ }^{34,35}$ lingual blockage of the mouthpiece, ${ }^{34}$ failure to hold the breath after inhaling). Patients who are cognitively impaired with neurologic alterations, frail, or simply unable to follow instructions, are likely to be more prone to these errors.
Effective dosing with a DPI requires an adequate peak inspiratory flow rate, which varies among devices. ${ }^{36,37}$ An initial peak inspiratory flow $>30 \mathrm{~L} / \mathrm{min}$ is considered the minimum necessary for effective dosing, and a peak inspiratory flow $\geq 60 \mathrm{~L} / \mathrm{min}$ is considered optimal to break up the dry powder into particles of $<5 \mu \mathrm{m}$ diameter that will be deposited into the lower airways. ${ }^{37}$ Older patients, especially those over the age of 80 years, may be unable to reach the $60 \mathrm{~L} / \mathrm{min}$ threshold. ${ }^{36,37} \mathrm{In}$ a recent study of 213 patients aged $\geq 60$ years (mean $70.1 \pm 6.9$ years) with advanced COPD ( $\mathrm{FEV}_{1}<50 \%$ predicted), 41 (19\%) were unable to generate the required peak inspiratory flow through the simulated resistance of a DPI. ${ }^{38}$ This subgroup of patients was predominantly female $(80 \%)$, were of shorter stature $(150 \mathrm{~cm})$, and had lower lung capacity (FVC $66 \%$ of predicted) than the subgroup of patients who were able to generate a peak inspiratory flow $\geq 60 \mathrm{~L} / \mathrm{min}$ ( $48 \%$ female, $166 \mathrm{~cm}$ tall, and FVC $77 \%$ of predicted). A low force of inspiration may result in insufficient drug deposition in the lung and excessive deposition in the patient's mouth or pharynx. ${ }^{34,37}$ This may lead to mouth dryness and adversely affect medication adherence. Swallowing the dose that remains in the oropharynx can contribute to systemic adverse events. Clinicians should spend time teaching patients how to use these devices and then confirm appropriate use in follow-up visits.

\section{Nebulizers}

The main types of nebulizers can be driven by compressed gas (jet nebulizer), an ultrasonically vibrating crystal (ultrasonic nebulizer), or a vibrating mesh (membrane). Although older devices were bulky, newer models are smaller, portable, and battery-operated. ${ }^{13}$

Once set up, nebulizers are easier for patients to use than handheld devices as they only require normal tidal respiration for effective drug delivery. ${ }^{39-41}$ Nebulizers offer a convenient way of delivering a higher dose to the airways, if necessary. ${ }^{41}$ The majority of patients in the emergency department, hospital, intensive care unit, or walk-in setting who need inhaled medication are treated with a nebulizer. Nebulizers are also effective for maintenance dosing in populations who are unable to use other devices, particularly in patients with cognitive, neuromuscular, or ventilatory impairments. A large percentage of patients (56\%) using nebulizers instead of other devices do so because of physical or cognitive disabilities. ${ }^{42}$

The disadvantages cited for nebulizers in the literature are not ones of patient use but rather the need for daily cleaning and longer time required for drug administration. ${ }^{13}$ 
Nebulizer use requires careful instructions on use and hygiene, as well as arrangements for maintenance and support. ${ }^{43}$ The assistance of a caregiver is required when used by physically or cognitively impaired patients. Despite these requirements, a recent survey of 82 patients who were using nebulizers found that $98 \%$ reported that the benefits of nebulizer use outweighed the disadvantages. ${ }^{39}$ With the exception of long-acting anticholinergic drugs, all approved classes of medications for COPD are available for administration by nebulizer (Table 3 ). ${ }^{3}$

\section{Choice of inhaled pharmacologic treatment in the elderly}

Table 2 presents the GOLD classification of risk based on spirometry, history of exacerbations, and symptom severity, along with suggested initial inhaled pharmacotherapy for

Table 3 Available formulations of inhaled COPD medications

\begin{tabular}{|c|c|c|c|}
\hline Drug & $\begin{array}{l}\text { Pressurized } \\
\text { MDI }\end{array}$ & DPI & Nebulizer \\
\hline \multicolumn{4}{|l|}{ Beta $_{2}$ agonists } \\
\hline \multicolumn{4}{|l|}{ Short-acting } \\
\hline Fenoterol & - & & $\bullet$ \\
\hline Levalbuterol & $\bullet$ & & • \\
\hline Salbutamol (albuterol) & $\bullet$ & $\bullet$ & - \\
\hline Terbutaline & & $\bullet$ & \\
\hline \multicolumn{4}{|l|}{ Long-acting } \\
\hline Formoterol & - & $\bullet$ & - \\
\hline Arformoterol & & & • \\
\hline Indacaterol & & • & \\
\hline Salmeterol & - & - & \\
\hline \multicolumn{4}{|l|}{ Anticholinergics } \\
\hline \multicolumn{4}{|l|}{ Short-acting } \\
\hline Ipratropium bromide & - & & - \\
\hline Oxitropium bromide & - & & - \\
\hline \multicolumn{4}{|l|}{ Long-acting } \\
\hline Tiotropium & - & & \\
\hline \multicolumn{4}{|l|}{ Corticosteroids } \\
\hline Beclomethasone & - & $\bullet$ & - \\
\hline Budesonide & & $\bullet$ & • \\
\hline Fluticasone & - & • & \\
\hline \multicolumn{4}{|l|}{ Combination products } \\
\hline \multirow{2}{*}{\multicolumn{4}{|c|}{$\begin{array}{l}\text { Short-acting beta }{ }_{2} \text { agonists plus } \\
\text { short-acting anticholinergic }\end{array}$}} \\
\hline & & & \\
\hline Fenoterol + ipratropium & - & & - \\
\hline Salbutamol + ipratropium & - & & - \\
\hline \multicolumn{4}{|l|}{$\begin{array}{l}\text { Long-acting beta }{ }_{2} \text { agonists plus } \\
\text { corticosteroids }\end{array}$} \\
\hline Formoterol + budesonide & - & • & \\
\hline Salmeterol + fluticasone & - & - & \\
\hline
\end{tabular}

Note: Reproduced with permission from the Global Initiative for Chronic Obstructive Lung Disease (GOLD). ${ }^{3}$

Abbreviations: COPD, chronic obstructive pulmonary disease; DPI, dry powder inhaler; MDI, metered dose inhaler. each of the risk classifications. ${ }^{3,12}$ Table 3 shows the currently available inhaled formulations of short-acting and long-acting beta ${ }_{2}$ agonists, short-acting and long-acting anticholinergics, corticosteroids, and various combination products. ${ }^{3}$ Meta-analyses comparing the clinical efficacy of medication delivered by pressurized MDIs, DPIs, or nebulizers have failed to show that the method of administration impacts outcomes. ${ }^{44}$ However, it is important to note that most studies on MDIs and DPIs have included only patients who demonstrated that they could use these devices properly and excluded patients who were cognitively impaired, neurologically altered, or otherwise unable to use the device. Therefore, the decision regarding which device should be used to treat the elderly COPD patient should be individualized to the patient's capabilities and preference. Assessment of the older person's ability to use their pressurized MDI or DPI should be integrated into the follow-up visit. Patients who remain unable to effectively use handheld inhalers despite instruction (eg, unable to coordinate inhalation with actuation of a pressurized MDI or unable to generate sufficient peak inspiratory flow to use a DPI) should be considered for nebulizer use. Nebulizers should be considered in all patients with cognitive impairment, inadequate manual dexterity due to arthritis, Parkinson's disease, or stroke, or who have manual weakness.

\section{Discussion}

Treatment of COPD with inhaled therapy should be customized to each older patient. The selection of inhaler device for these patients should be influenced by their cognitive, physical, and educational abilities. MDIs and DPIs are the most rapid and most practical way of delivering medication. They are the first choice for those patients who show that they can follow and, as importantly, remember instructions. However, for elderly patients, especially those with cognitively impairment and/or with hand arthritis, neurologic conditions, or frailty, MDIs and DPIs present many challenges. Moreover, confirmation that they are using them correctly in follow-up visits is critical. This could be a challenge for clinicians with busy schedules, and patients may not be adequately overseen. If patients cannot use MDIs and DPIs properly, they will not be able to properly receive the therapy. These patients should be evaluated for nebulized therapy instead. Both rescue and maintenance therapies can be delivered with a nebulizer. In our experience, failure to prescribe maintenance therapy is common, leading to the abuse of rescue medications to fulfill maintenance needs. 


\section{Conclusion}

In COPD, inhaled therapies are the cornerstone of treatment. While a wide choice of inhalation devices is available, patient's preferences and functional and cognitive capabilities may influence the choice of device. Maintenance therapy is important to patient outcomes and should be incorporated into the treatment plan.

In patients who are prescribed an MDI or DPI, it is incumbent on the care team to give instruction to both patients and caregivers and assess the use of the device to see whether it is being used correctly. Otherwise, nebulizers may be the means to provide drugs with the greatest ease for elderly patients.

\section{Acknowledgments}

The authors acknowledge the writing and editorial assistance provided by Genevieve Belfiglio and Edward Weselcouch of PharmaWrite, LLC (Princeton, NJ), which was funded by Mylan Specialty L.P. This manuscript was prepared according to the International Society for Medical Publication Professionals' "Good Publication Practice for Communicating CompanySponsored Medical Research: The GPP2 Guidelines”.

\section{Disclosure}

GET reports no conflicts of interest in this work. JFD is a consultant to Mylan Specialty L.P., AstraZeneca, Boehringer Ingelheim, GlaxoSmithKline, Forest, Novartis, Pearl, Pfizer, and Sunovion, and is a Data and Safety Monitoring Board member for Novartis, Pearl, Teva, Otsuka, and PulmoNx. PRA was employed by Mylan Specialty L.P. during the drafting of this manuscript.

\section{References}

1. Akinbami LJ, Liu X. Chronic obstructive pulmonary disease among adults aged 18 and over in the United States, 1998-2009. NCHS Data Brief. 2011;63:1-8.

2. Centers for Disease Control and Prevention, National Center for Health Statistics. Data brief 63: chronic obstructive pulmonary disease among adults aged 18 and over in the United States, 1998-2009. Available from: http://www.cdc.gov/nchs/data/databriefs/db63_tables.pdf\#2. Accessed August 8, 2013.

3. Global Initiative for Chronic Obstructive Lung Disease. Global strategy for the diagnosis, management, and prevention of chronic obstructive pulmonary disease. 2013. Available from: http:/www.goldcopd.org/ guidelines-global-strategy-for-diagnosis-management.html. Accessed August 30, 2013.

4. Bourbeau J, Bartlett SJ. Patient adherence in COPD. Thorax. 2008; 63(9):831-838.

5. Janssens JP. Aging of the respiratory system: impact on pulmonary function tests and adaptation to exertion. Clin Chest Med. 2005;26(3):469-vii.

6. Sharma G, Goodwin J. Effect of aging on respiratory system physiology and immunology. Clin Interv Aging. 2006;1(3):253-260.

7. Hankinson JL, Odencrantz JR, Fedan KB. Spirometric reference values from a sample of the general US population. Am J Respir Crit Care Med. 1999;159(1):179-187.
8. Pezzoli L, Giardini G, Consonni S, et al. Quality of spirometric performance in older people. Age Ageing. 2003;32(1):43-46.

9. Allen SC, Baxter M. A comparison of four tests of cognition as predictors of inability to perform spirometry in old age. Age Ageing. 2009; 38(5):537-541.

10. Tombaugh TN, McIntyre NJ. The Mini-Mental State Examination: a comprehensive review. J Am Geriatr Soc. 1992;40(9):922-935.

11. Qaseem A, Wilt TJ, Weinberger SE, et al. Diagnosis and management of stable chronic obstructive pulmonary disease: a clinical practice guideline update from the American College of Physicians, American College of Chest Physicians, American Thoracic Society, and European Respiratory Society. Ann Intern Med. 2011;155(3):179-191.

12. Brocklebank D, Ram F, Wright J, et al. Comparison of the effectiveness of inhaler devices in asthma and chronic obstructive airways disease: a systematic review of the literature. Health Technol Assess. 2001; 5(26):1-149.

13. Barrons R, Pegram A, Borries A. Inhaler device selection: special considerations in elderly patients with chronic obstructive pulmonary disease. Am J Health Syst Pharm. 2011;68(13):1221-1232.

14. Zarowitz BJ, O'Shea T. Chronic obstructive pulmonary disease: prevalence, characteristics, and pharmacologic treatment in nursing home residents with cognitive impairment. $J$ Managed Care Pharm. 2012;18(8):598-606.

15. Restrepo RD, Alvarez MT, Wittnebel LD, et al. Medication adherence issues in patients treated for COPD. Int J Chron Obstruct Pulmon Dis. 2008;3(3):371-384.

16. George J, Kong DC, Thoman R, Stewart K. Factors associated with medication nonadherence in patients with COPD. Chest. 2005;128(5):3198-3204.

17. Centers for Disease Control and Prevention. Annual smokingattributable mortality, years of potential life lost, and productivity losses - United States, 1997-2001. MMWR Morb Mortal Wkly Rep. 2005;54(25):625-628.

18. Gentil L, Vasiliadis HM, Preville M, Bosse C, Berbiche D. Association between depressive and anxiety disorders and adherence to antihypertensive medication in community-living elderly adults. $J$ Am Geriatr Soc. 2012;60(12):2297-2301.

19. Bosley CM, Corden ZM, Rees PJ, Cochrane GM. Psychological factors associated with use of home nebulized therapy for COPD Eur Respir J. 1996;9(11):2346-2350.

20. Allen SC. Competence thresholds for the use of inhalers in people with dementia. Age Ageing. 1997;26(2):83-86.

21. Dodd JW, Getov SV, Jones PW. Cognitive function in COPD. Eur Respir J. 2010;35(4):913-922.

22. Villeneuve S, Pepin V, Rahayel S, et al. Mild cognitive impairment in moderate to severe COPD: a preliminary study. Chest. 2012;142(6): $1516-1523$.

23. Gray SL, Williams DM, Pulliam CC, Sirgo MA, Bishop AL, Donohue JF. Characteristics predicting incorrect metered-dose inhaler technique in older subjects. Arch Intern Med. 1996;156(9):984-988.

24. Barr RG, Celli BR, Mannino DM, et al. Comorbidities, patient knowledge, and disease management in a national sample of patients with COPD. Am J Med. 2009;122(4):348-355.

25. Brennan VK, Osman LM, Graham H, Critchlow A, Everard ML. True device compliance: the need to consider both competence and contrivance. Respir Med. 2005;99(1):97-102.

26. Giraud V, Roche N. Misuse of corticosteroid metered-dose inhaler is associated with decreased asthma stability. Eur Respir J. 2002;19(2): 246-251.

27. Wieshammer S, Dreyhaupt J. Dry powder inhalers: which factors determine the frequency of handling errors? Respiration. 2008;75(1):18-25.

28. Chapman KR, Voshaar TH, Virchow JC. Inhaler choice in primary practice. Eur Respir Rev. 2005;14(96):117-122.

29. Hess DR. Metered-dose inhalers and dry powder inhalers in aerosol therapy. Respir Care. 2005;50(10):1376-1383.

30. Todd MA, Baskett JJ, Richmond DE. Inhaler devices and the elderly $N Z$ Med J. 1990;103(883):43-46. 
31. Yawn BP, Colice GL, Hodder R. Practical aspects of inhaler use in the management of chronic obstructive pulmonary disease in the primary care setting. Int J Chron Obstruct Pulmon Dis. 2012:7495-7502.

32. Gray SL, Nance AC, Williams DM, Pulliam CC. Assessment of interrater and intrarater reliability in the evaluation of metered dose inhaler technique. Chest. 1994;105(3):710-714.

33. Atkins PJ. Dry powder inhalers: an overview. Respir Care. 2005; 50(10):1304-1312.

34. Lavorini F, Magnan A, Dubus JC, et al. Effect of incorrect use of dry powder inhalers on management of patients with asthma and COPD. Respir Med. 2008;102(4):593-604.

35. Broeders ME, Vincken W, Corbetta L. The ADMIT series - Issues in Inhalation Therapy. 7. Ways to improve pharmacological management of COPD: the importance of inhaler choice and inhalation technique. Prim Care Respir J. 2011;20(3):338-343.

36. Janssens W, VandenBrande P, Hardeman E, et al. Inspiratory flow rates at different levels of resistance in elderly COPD patients. Eur Respir J. 2008;31(1):78-83.

37. Al-Showair RA, Tarsin WY, Assi KH, Pearson SB, Chrystyn H. Can all patients with COPD use the correct inhalation flow with all inhalers and does training help? Respir Med. 2007;101(11):2395-2401.
38. Mahler DA, Waterman LA, Gifford AH. Prevalence and COPD phenotype for a suboptimal peak inspiratory flow rate against the simulated resistance of the Diskus(®) dry powder inhaler. J Aerosol Med Pulm Drug Deliv. 2013;26(3):174-179.

39. Filuk R. Delivery system selection: clinical considerations. Am Health Drug Benefits. 2008;1(Suppl 8):13-17.

40. Rau JL. Practical problems with aerosol therapy in COPD. Respir Care. 2006;51(2):158-172.

41. Dolovich MB, Dhand R. Aerosol drug delivery: developments in device design and clinical use. Lancet. 2011;377(9770):1032-1045.

42. Bowles SK, Sketris I, Kephart G. Use of wet nebulized inhaled respiratory medications under criteria-based reimbursement guidelines in a publicly funded Seniors' Pharmacare Program in Nova Scotia, Canada. Am J Geriatr Pharmacother. 2007;5(2):120-128.

43. Rees J. ABC of asthma. Methods of delivering drugs. BMJ. 2005; 331(7515):504-506.

44. Dolovich MB, Ahrens RC, Hess DR, et al. Device selection and outcomes of aerosol therapy: evidence-based guidelines: American College of Chest Physicians/American College of Asthma, Allergy, and Immunology. Chest. 2005;127(1):335-371.
Clinical Interventions in Aging

\section{Publish your work in this journal}

Clinical Interventions in Aging is an international, peer-reviewed journal focusing on evidence-based reports on the value or lack thereof of treatments intended to prevent or delay the onset of maladaptive correlates of aging in human beings. This journal is indexed on PubMed Central, MedLine, the American Chemical Society's 'Chemical Abstracts

\section{Dovepress}

Service' (CAS), Scopus and the Elsevier Bibliographic databases. The manuscript management system is completely online and includes a very quick and fair peer-review system, which is all easy to use. Visit $\mathrm{http}: / /$ www.dovepress.com/testimonials.php to read real quotes from published authors. 